\title{
Fixing the climate odds
}

\section{Gail Whiteman welcomes a take on climate economics that is strong on strategy.}

$\mathrm{T}$ he power of intelligent economics permeates William Nordhaus's The Climate Casino. In it, he presents an overview of climate science, economic theory and modelling, and outlines a number of economic strategies to resolve our climate challenges. He argues that economic growth is driving "unintended but perilous changes in the climate and earth systems" - and that we are, effectively, "rolling the climatic dice".

Not all may agree with this metaphor. But for US audiences in particular, the book convincingly makes the economic case for changing governmental policy, and our production and consumption habits, by offering economic incentives for low-carbon choices. The market alone cannot account for externalities stemming from climate change, such as ocean acidification, without being prodded by measures such as carbon taxes.

More debatable is what Nordhaus says about keeping the maximum global average temperature to $2{ }^{\circ} \mathrm{C}$ above pre-industrial levels - a target of the Copenhagen Accord, the political compromise resulting from the 2009 United Nations Climate Change conference. Nordhaus views this goal as primarily political, and not well grounded in natural science, although numerous climate studies do support it. He suggests instead a rise of just under $3^{\circ} \mathrm{C}$, as the review by Timothy $\mathrm{M}$. Lenton and colleagues (T. M. Lenton et al. Proc. Natl Acad. Sci. USA 105, 1786-1793; 2008) indicates that below it, large-scale tipping points such as widespread dieback in the Amazonian rainforest are unlikely.

But Nordhaus misses the point here. There is more to threshold setting than the avoidance of isolated tipping points. For example, the "planetary boundaries" model of Johan Rockström and others defines a "safe operating space" for humanity by pinpointing nine interlinked boundaries in Earth systems beyond which irreversible damage occurs (J. Rockström et al. Ecol. Soc. 14, 32; 2009).

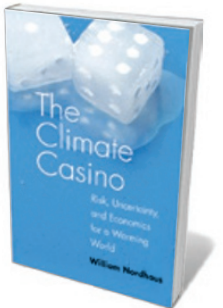

The Climate Casino: Risk, Uncertainty, and Economics for a Warming World WILLIAM NORDHAUS Yale University Press: 2013.

for example. It is unfortur the book's timing precludes the inc reports by the Intergovernmental Panel on Climate Change Working Groups I and II (released last month and due in March 2014, respectively), as these would strengthen the chapters on climate science and impacts.

In his discussions on the strategies, costs, policies and institutions involved in slowing climate change, Nordhaus relies on his own integrated economic and geophysical model of climate-change economics, DICE (Dynamic Integrated model of Climate and the Economy). He offers a convincing comparison of carbon tax and cap-and-trade options, concluding that both are equally useful. And he argues strongly for a carbon price of US $\$ 25$ per tonne, using a $4 \%$ discount rate to bring future costs back to present-day dollars. However, other analysts support a much higher price for carbon and a lower discount rate, such as the one used in Nicholas Stern's groundbreaking 2006 review Economics of Climate Change. Nordhaus concludes: "We should aim for a lower temperature target if it is inexpensive, but we might have to live with a higher target if costs are high or policies are ineffective." Although he is sensitive to the normative judgements of others, he does not perceive any normative sentiment in his own work.

Nordhaus's impassioned review of the politics around government (in)action on climate change and climate scepticism is largely US-centric. A more detailed analysis of the dramatic drop in European carbon prices in April 2012, following a decision by the European Parliament, would be welcome, for instance. What is interesting for all of us is Nordhaus's emphatic re-confirmation that his research using DICE does not support the position of climate sceptics, despite its use by some of these camps to argue that because climate change has economic benefits, there is no need to curb it.

Nordhaus is right in saying that economic incentives facilitate and encourage low-carbon behaviour. But managing climate change demands more. Markets are influenced by regulations and changes in accounting and valuation techniques that determine new rules of the game. The question of how best to deal with the thorny issue of stranded assets - obsolete or overvalued assets such as nonviable coal plants - remains unanswered in this book. Another missed opportunity is a deeper engagement with management theory, which has empirically shown that corporate behaviour across various industry sectors is driven by values, biases, emotions, culture and hyper-competitiveness as well as the pursuit of profit. Without delving deeper into corporate boardrooms, we are left wondering where change will come from if governments, as the architects of global policy frameworks, remain deadlocked.

Gail Whiteman is professor-in-residence at the World Business Council for Sustainable Development in Geneva, Switzerland, and is Chair in Sustainability and Climate Change at Erasmus University, the Netherlands. e-mail:gwhiteman@rsm.nl

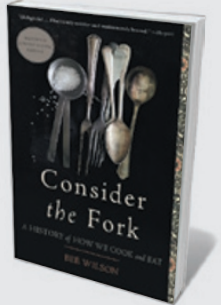

Consider the Fork: A History of How We Cook and Eat

Bee Wilson (Basic Books, 2013)

Food historian Bee Wilson looks at how need sparks culinary innovation. She reveals, for instance, that China's lack of firewood led to the ultimate 'fast food' technique, stir-frying. (See Barbara Ketcham Wheaton's review: Nature 489, 500; 2012.)

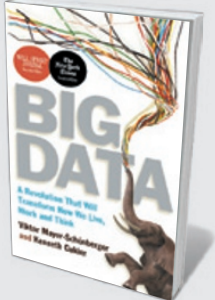

Big Data: A Revolution That Will Transform How We Live, Work and Think Viktor Mayer-Schönberger and Kenneth Cukier (John Murray Publishers, 2013)

Big data is key to numerous fields and socialnetworking sites. Among many case studies, the authors contend that Google Flu Trends monitors influenza's spread better than traditional systems. 